Session: 3565

\title{
Using the History of Calculus as an Aid for Teaching Dynamics
}

\author{
Maximo J. Ortega \\ Purdue University
}

Introduction

Nowadays, Calculus teaching has become a real challenge. Experiences in the classroom show that students consider Calculus a never-ending succession of techniques or, as they usually say, "recipes". Most of the problems presented do not have any "real" meaning for them. 1,2

Frequently the teacher introduces these problems by using Geometry. ${ }^{3,4,5}$ This approach is sometimes very useful, however its scope is rather limited to some very specific applications. Geometry alone cannot represent the importance of Calculus in the development of Science and Technology. The student may learn the methodology, remember the formula, and find the tangent equation or any other task assigned by his teacher. But sooner or later, the student will ask the question, "what am I going to do with this?" Freudenthal mentions that a considerable amount of research has been done about the learning process but most of this research has been more lab-oriented than classroom-oriented. Very little is known about how an individual applies what he or she has learned. This knowledge is the key to understanding why many people never successfully apply their theoretical knowledge ${ }^{6}$.

In summary, there is a lot of controversy about the way Calculus should be taught. Without disregarding other possible deficiencies, it can be considered that one of the main issues is the deep disassociation between the mathematical models being taught and the causes that motivated the creation of these models. This motivation is something that many students do not perceive at all. Cantoral et al. pointed out that it is important to understand the circumstances that allowed the building of the knowledge, instead of merely knowing the circumstances that facilitated its evolution ${ }^{7}$. Attention must be focused on the initial stages of an idea. These initial stages always involve intuition and every day experiences but with the development of theoretic formulations the idea evolves into the base argument of theoretic results. This evolutionary process eventually conceals the original meaning. Sometimes, theoretic results are shown in the classroom while the original idea is ignored.

Another issue that emphasizes the importance of new teaching approaches is the fact that most students find it very difficult to apply their knowledge of Calculus in other courses. When faced with a problem that requires them to find a derivative or calculate an integral, many students

"Proceedings of the 2002 American Society for Engineering Education Annual Conference \& Exposition Copyright @ 2002, American Society for Engineering Education" 
will ask for an alternative methodology that does not rely on Calculus. This behavior indicates that they see Calculus as isolated, having little or no relation to the rest of the knowledge they are trying to learn. In many cases, however, Calculus is the basis for the development of this knowledge. They know how to solve the problems but they do not understand what is behind the methodology.

The history of Mathematics teaches without doubt that Calculus concepts and methods had an empirical beginning. Therefore, Calculus can be taught by using some of the ideas that motivated this beginning. This work also shows that ideas from the history of calculus can be used to teach concepts in other courses. Specifically, an alternative method of teaching a concept from Dynamics is presented. This alternative applies an intuitive idea that was basic for the development of Calculus: Taylor's Series. A classroom experience is described and it is shown that the level of concept understanding is greatly enhanced

\section{Problem statement}

Archimedes, "the divine", was not able to elaborate on Dynamics, but merely Statics. He created a repose theory, not a movement theory ${ }^{8}$. It is evident that the study of movement always represented serious difficulty, even for the great minds in history. In order to develop a theory of movement, it was sometimes necessary to go against intuition. It can be pointed out that even Newton gave importance to intuition. At the beginning of Principia Mathematica he mentions that time, space, location, and movement are not going to be defined, given that everyone knows these concepts perfectly well ${ }^{9}$. However, Newton also adds that common people perceive these concepts through the relationship they maintain with sensible objects.

Modern mechanic principles and concepts are so well known that it is almost impossible to imagine the difficulties that were overcome to establish these ideas. Principles look so simple and so natural that it is sometimes easy to miss the paradoxes they imply. However, the simple fact that some of the biggest and most powerful spirits of humanity struggled with these concepts should be enough to prove that they are not so simple and clear as they may seem ${ }^{8}$. If these big thinkers did not fully understand the essence of movement, is it realistic to expect students to grasp these concepts immediately?

This work focuses on a common misconception observed among undergraduate students in a Dynamics course. This misconception is associated with the confusion between movement and velocity. At the beginning of the class, it is emphasized that movement, for study purposes, is divided into three elements: Position, the body coordinates; Velocity, the position rate of change with regard to time; and Acceleration, the velocity rate of change with regard to time. However, students tend to mix the concepts of velocity and movement by identifying them as the same. It was detected that this misconception leads students to believe that it is not possible to have acceleration when velocity is equal to zero. Students saw it as obvious that there could be velocity when there is no acceleration. They immediately identified this case as movement with constant velocity. In the same way, the remaining combinations, $\mathrm{v}\left(\mathrm{t}_{\mathrm{o}}\right)=0$ with $\mathrm{a}\left(\mathrm{t}_{\mathrm{o}}\right)=0$, and $\mathrm{v}\left(\mathrm{t}_{\mathrm{o}}\right)$ $\neq 0$ with $\mathrm{a}\left(\mathrm{t}_{\mathrm{o}}\right) \neq 0$, were easily identified as repose and accelerated movement, respectively.

"Proceedings of the 2002 American Society for Engineering Education Annual Conference \& Exposition Copyright (C) 2002, American Society for Engineering Education" 
Therefore, the case with acceleration but no velocity is the only one that presented difficulties. Persons familiar with Physics or Mechanics have no problem with this situation. It represents either a condition of imminent movement or a change of direction (for rectilinear movement). However, in order for this change to be possible, acceleration must be different from zero, otherwise the body remains in repose. These concepts may seem quite simple, but for most students, they are rather complicated.

After teaching this class for several semesters, the misconception was always present in the courses taught. Hence, it was evident that some didactic tool was needed to clarify the idea that acceleration can exist without velocity. It was in the context of this search that Taylor's Series came into the picture. This technique may seem like an out of place element in a Dynamics course and perhaps even in a Calculus course. While Taylor's Series could have a central role in the development of the main concepts and theorems presented in a Calculus class, a review of the more popular textbooks adopted for Calculus courses shows that Taylor's Series, when mentioned, is usually disconnected from the rest of the textbook. Usually it is only mentioned when covering the topic of convergence for infinite series. But attention is centered on convergence concepts and eventually on approximations by using polynomials within a given interval ${ }^{10}$.

This presentation suggests that Taylor's Series is not basic and that it has no use in the solution of problems or in theorem demonstrations. On the other hand, Physics and Engineering textbooks eventually present notions of Taylor's Series that suggest its application as an instrument for prediction instead of an object of convergence as it is presented in Mathematics textbooks. An example of this kind of argument is the statement that “... if $p$ represents a certain physical parameter on a given time instant $\mathrm{t}$, a moment later $\mathrm{t}+\mathrm{dt}$, this parameter will be $p+$ $\mathrm{d} p$ ". Movement in general and flow phenomena have heritage. In other words, the next state of the phenomenon depends upon the circumstances that characterize the current state. Hence, there is a need for an instrument of predictive nature to study variation phenomena and changes in nature ${ }^{7}$.

In this way, Calculus seems to go back to its origins. Prediction is the idea employed in order to bring the concept of Taylor's Series closer to the students. In other words, the initial values of a system in evolution allow for the identification of the system's future state. It can be seen that this idea is clear when studying the equations of particle kinematics ${ }^{11}$. It is now evident that Taylor's Series can be closely related to a Dynamics course. In this case, Taylor's Series is not the central idea, but an intuitive aid that may enable the students to grasp some very difficult concepts of movement.

Theoretic framework

A Dynamics course usually has the following structure: the class is conceptually divided into two parts - the study of particles and the study of rigid bodies. In other words, movement is first studied without considering the shape of the body that is moving. Once the basic elements of movement are understood, the shape of the body is also included as part of the analysis. The first method yields very good approximations, provided that the size of the trajectory is considerably larger than the size of the body. Now, the topics of particles and rigid bodies are themselves

"Proceedings of the 2002 American Society for Engineering Education Annual Conference \& Exposition Copyright @ 2002, American Society for Engineering Education" 
divided into three conceptual parts: Kinematics, which is the study of pure movement without considering its source; Kinetics, which is the analysis of the relationship between movement and the forces that originate it based on Newton's second law of motion; and Energy and Momentum Methods, which are alternative techniques used to answer some problems that require Calculus to be solved.

Three Dynamics textbooks were reviewed ${ }^{12,13,14}$. It was observed that none of the textbooks, even those that deeply explored the topics, presented elements to explain the condition being studied. The issue is only mentioned in an indirect way. The application of limits to explain the concepts of velocity and acceleration is widespread, which coincides with the traditional approach to Calculus. Regarding Taylor's Series, some textbooks mention " $\mathrm{v}+\Delta \mathrm{v}$ in $\mathrm{t}+\Delta \mathrm{t}$ " which bears a slight resemblance to the Series. However, none of the textbooks mention the Taylor's Series nor the concept of prediction at all. It was also considered important to look at some textbooks from the high school level ${ }^{15,16,17}$, when the study of movement is usually introduced in a basic Physics course. These high school textbooks briefly, mention the idea of prediction, but ultimately they present velocity and acceleration by using variations of the same traditional approach employed in Dynamics textbooks. When physics is taught, the teacher must emphasize the physical phenomenon and describe this phenomenon by using a mathematic formalism. However, the teacher is usually only marginally successful in the qualitative explanation of the phenomenon ${ }^{18}$.

Now, the proposed Taylor's Series approach will be described. Cantoral ${ }^{10}$ mentions that if from the beginning of movement, values assumed by position $S(0)=S_{0}$, velocity $V(0)=V_{0}$, and acceleration $\mathrm{a}(0)=\mathrm{a}$ are known, then the position at any given instant $\mathrm{t}$ is $\mathrm{S}(\mathrm{t})$. The functional expression for $\mathrm{S}(\mathrm{t})$ will be given by the natural prediction instrument: Taylor's Series,

$$
S(t)=S(0)+S^{\prime}(0) t+S^{\prime},(0) t^{2} / 2 !+\ldots
$$

When dealing with rectilinear movement uniformly accelerated, for every $t$ value it is found that,

$$
\mathrm{S}^{(\mathrm{n})}(\mathrm{t})=0 \quad \forall \mathrm{n} \geq 3
$$

Therefore, equation (1) can be expressed as,

$$
S(t)=S(0)+S^{\prime}(0) t+S^{\prime}(0) t^{2} / 2 !
$$

By making some notational adjustments, it can be shown that,

$$
\mathrm{S}(\mathrm{t})=\mathrm{S}_{\mathrm{o}}+\mathrm{v}_{\mathrm{o}} \mathrm{t}+1 / 2 a \mathrm{t}^{2}
$$

The idea of prediction could be more general if several parameters were known for a given point, let us say $x_{0}$. Then, these parameters could be employed to announce the state at the next point, that is $x_{\mathrm{o}}+\mathrm{h}$. Hence, if the following values are known, $x_{\mathrm{o}}, \mathrm{h}, \mathrm{f}\left(x_{\mathrm{o}}\right), \mathrm{f}^{\prime}\left(x_{\mathrm{o}}\right), \mathrm{f}^{\prime}$ ' $\left(x_{\mathrm{o}}\right)$, etc. then it is possible to find the next value of the variable represented by the function $\mathrm{f}(x)$. In other words,

$$
\mathrm{f}\left(x_{\mathrm{o}}+\mathrm{h}\right)=\mathrm{f}\left(x_{\mathrm{o}}\right)+\mathrm{f}^{\prime}\left(x_{\mathrm{o}}\right) \mathrm{h}+\mathrm{f}^{\prime}{ }^{\prime}\left(x_{\mathrm{o}}\right) \mathrm{h}^{2} / 2 !+\ldots
$$

Using these ideas as a starting point, a presentation was made in the classroom. At the beginning, a brief explanation was made about the structure of Taylor's Series. It was emphasized that this was originally an instrument used for prediction purposes. If initial values for $x_{\mathrm{o}}$ and $\mathrm{f}\left(x_{\mathrm{o}}\right)$ are known, then it is possible to find the future value of the function, even without knowing the

"Proceedings of the 2002 American Society for Engineering Education Annual Conference \& Exposition Copyright (C) 2002, American Society for Engineering Education" 
specific form of the function $\mathrm{f}(x)$, provided that the value for the rate of change in $x_{\mathrm{o}}\left[\mathrm{f}^{\prime}\left(x_{\mathrm{o}}\right)\right]$ and the rate of change of this rate of change [ $\left.\mathrm{f}^{\prime}\left(x_{\mathrm{o}}\right)\right]$ are also known. An example was introduced by presenting a case where an expression provides the position as a function of time. In other words, for every $t$ value, the formula returns the position value. For example,

$$
\begin{array}{rlrl}
\mathrm{S}(\mathrm{t}) & =3 \mathrm{t}^{2}-\mathrm{t}+1 & \\
\text { If } \mathrm{t} & =0, \mathrm{~S}(0)=3(0)^{2}-0+1 & & \mathrm{~S}(0)=1 \\
\text { If } \mathrm{t} & =1, \mathrm{~S}(1)=3(1)^{2}-1+1 & & \therefore \mathrm{S}(1)=3 \\
\text { If } \mathrm{t} & =2, \mathrm{~S}(2)=3(2)^{2}-2+1 & \therefore \mathrm{S}(2)=11 \\
\text { If } \mathrm{t}=3, \mathrm{~S}(3)=3(3)^{2}-3+1 & \therefore \mathrm{S}(3)=25
\end{array}
$$

Next, it was assumed that the function $\mathrm{S}(\mathrm{t})$ was not known. Only the rate of change of the function as well as the rate of change of the rate of change in $t=0$ are known. Taylor's Series must then be sufficient to calculate the positions value for $t=1,2, \ldots$ The rate of change is the first derivative of the function and the rate of change of the rate of change is the second derivative of the function. Then,

$$
\begin{array}{ll}
S^{\prime}(t)=6 t-1 & \therefore S^{\prime}(0)=-1 \\
S^{\prime}(t)=6 & \therefore S^{\prime}{ }^{\prime}(0)=6
\end{array}
$$

In this way, predicting the values according to the Series was done as follows,

$$
\begin{aligned}
& S(1)=S(0)+S^{\prime}(0) t+1 / 2 S^{\prime}{ }^{\prime}(0) t^{2}=1-1(1)+1 / 2(6)(1)^{2}=3 \\
& S(2)=S(0)+S^{\prime}(0) t+1 / 2 S^{\prime} \prime(0) t^{2}=1-1(2)+1 / 2(6)(2)^{2}=11 \\
& S(3)=S(0)+S^{\prime}(0) t+1 / 2 S^{\prime}{ }^{\prime}(0) t^{2}=1-1(3)+1 / 2(6)(3)^{2}=25
\end{aligned}
$$

This numerical presentation confers to the student confidence in the Series. The student can see that the Taylor's Series is a valid approach to predicting the position at any given moment. Given that many students were not already familiar with the Series, this numerical presentation was a good way to introduce them to the technique. Also, most students are more prone to receive and accept empiric corroborations like this rather than a mathematic demonstration based on deduction and logic ${ }^{7}$.

The next step was to analyze the four cases using Taylor's Series:

If $\mathrm{v}\left(\mathrm{t}_{\mathrm{o}}\right)=0$ and $\mathrm{a}\left(\mathrm{t}_{\mathrm{o}}\right)=0$, then,

$$
\mathrm{S}(\mathrm{t})=\mathrm{S}(0)+\mathrm{S}^{\prime}(0) \overrightarrow{\mathrm{t}}+\mathrm{S}^{\prime},(0) \mathrm{t}^{2} / 2 ! \quad \therefore \mathrm{S}(\mathrm{t})=\mathrm{S}(0)
$$

In other words, the position does not change after $t$ seconds because the particle is in repose. If $\mathrm{v}\left(\mathrm{t}_{\mathrm{o}}\right) \neq 0$ and $\mathrm{a}\left(\mathrm{t}_{\mathrm{o}}\right)=0$, then,

$$
\mathrm{S}(\mathrm{t})=\mathrm{S}(0)+\mathrm{S}^{\prime}(0) \mathrm{t}+\mathrm{S}^{\prime}(0) \mathrm{t}^{2} / 2 \text { ! }
$$

Therefore the position varies according to the formula for constant velocity, $v=S / t$ and from this it can be solved $\mathrm{S}=\mathrm{vt}$, given that $\mathrm{v}=\mathrm{S}$ '. This corresponds to the expression obtained above. If $\mathrm{v}\left(\mathrm{t}_{\mathrm{o}}\right) \neq 0$ and $\mathrm{a}\left(\mathrm{t}_{\mathrm{o}}\right) \neq 0$, then,

$$
S(t)=S(0)+S^{\prime}(0) t+S^{\prime},(0) t^{2} / 2 !
$$

Hence position varies according to the values of velocity $\left[S^{\prime}(0)\right]$ and acceleration $\left[S^{\prime \prime}(0)\right]$. Also, it can be seen that this expression corresponds term by term to the equation of position as a function of time for uniformly accelerated motion,

"Proceedings of the 2002 American Society for Engineering Education Annual Conference \& Exposition Copyright $(\mathrm{C}$ 2002, American Society for Engineering Education" 


$$
S=S_{0}+v_{0} t+1 / 2 a t^{2}
$$

Finally, if $\mathrm{v}\left(\mathrm{t}_{\mathrm{o}}\right)=0$ and $\mathrm{a}\left(\mathrm{t}_{\mathrm{o}}\right) \neq 0$, then,

$$
\mathrm{S}(\mathrm{t})=\mathrm{S}(0)+\mathrm{S}^{\prime}(0) \overrightarrow{\mathrm{t}}^{0}+\mathrm{S}^{\prime \prime}(0) \mathrm{t}^{2} / 2 !
$$

It can be clearly observed that if $S^{\prime \prime}(0)$, that is, the acceleration, is also zero then $S(t)=S(0)$. This was the case when the particle was in repose. Now, if $\mathrm{a}\left(\mathrm{t}_{\mathrm{o}}\right) \neq 0 \mathrm{~S}(\mathrm{t})$ is going to change and its value is going to be $S(t)=S(0)+S^{\prime}$ ' $(0) t^{2} / 2$, obviously the new position will be different from $S(0)$ due to the term $S^{\prime}$ ' $(0)$. The series allows this condition to be shown without any association to the concept of instant as a differential time interval. Instead, the condition is associated with a specific value of the function $\mathrm{S}(\mathrm{t})$.

\section{Methodology}

Implementation of Taylor's Series as a didactic aid was begun over two summers. In the first summer there were two sections for the Dynamics course. One section was a morning class, and the other an afternoon class. There were 24 and 23 students registered respectively in each section. Both sections followed exactly the same syllabus. The only difference was that in the morning class, the Taylor's Series was used to explain the condition $v(0)=0$ and $a(0) \neq 0$. The concept was also explained to the other group but using a more traditional approach based on Calculus. In order to observe the effect of this change, surveys were administered at the beginning and at the end of the summer session. The initial and the final survey were identical and included 12 questions. In these surveys, question number 6 directly asked the students:

Is it possible for a body to have acceleration and not have velocity?

When this experiment was developed there was a question about whether having a morning and an afternoon section could affect the results. Therefore, in the second summer, data was collected using two morning sections of the same course. In order to establish a comparison with the previous year, none of these new groups received the explanation using Taylor's Series. The same survey was given, again at the beginning and at the end of the summer session. In sum, there were 3 groups that did not use Taylor's Series and one group that did and a total of 8 surveys were applied, two for each group (before and after the summer session).

The statistical analysis of the results from all the applied surveys is presented below. The statistical test applied was a Chi-Square for the equality of proportions. Initially, the behavior of the three groups that did not apply the Series was analyzed. Table 1 summarizes the information from these three groups. Each row represents a survey, columns 2 to 4 show the answer to question 6, the last column indicates if the survey was applied before or after the summer session, and finally, at the bottom of the table the percentage obtained for each answer is also indicated. The degrees of freedom for this table can be calculated as follows,

$$
\mathrm{g}_{\text {lib }}=(\text { columns }-1)(\text { rows }-1)=(2)(5)=10
$$

With these degrees of freedom and using a confidence level of 95\%, from a standard table for the Chi-square distribution the following statistic can be found:

$$
\mathrm{X}_{0.95}^{2}=18.31
$$

"Proceedings of the 2002 American Society for Engineering Education Annual Conference \& Exposition Copyright $@$ 2002, American Society for Engineering Education” 
Table 2 shows the expected values as well as the computations made in order to obtain the calculated statistic. The expected values were obtained by multiplying the percentage for the answer from Table 1 by the number of students in the corresponding section. The calculated statistic is smaller than the statistic obtained from standard tables for the Chi- square distribution $(17.3335<18.31)$. Therefore, it can be concluded that there is no difference

Table 1: Survey results for the sections that did not use Taylor's series.

\begin{tabular}{|c|c|c|c|c|c|}
\hline & \multicolumn{3}{|c|}{ Answers to Question 6} & \\
\hline Section & Yes & No & Don't Know & Totals & Situation \\
\hline 1 & 3 & 20 & 0 & 23 & Before \\
\hline 1 & 4 & 19 & 0 & 23 & After \\
\hline 2 & 7 & 20 & 0 & 27 & Before \\
\hline 2 & 11 & 16 & 0 & 27 & After \\
\hline 3 & 4 & 21 & 2 & 27 & Before \\
\hline 3 & 5 & 22 & 0 & 27 & After \\
\hline & 34 & 118 & 2 & 154 & \\
\hline
\end{tabular}

in the behavior of the sets of data. In other words, there is no significant difference among the three groups that did not use Taylor's Series. The fact that some of them were morning sections did not have any observable effect. Also, there is no difference among the results obtained before the session and after the session with regard to the understanding of the condition $\mathrm{v}(0)=0$ and $\mathrm{a}(0) \neq 0$.

Table 2: Expected value calculations for the sections that did not use Taylor's series.

\begin{tabular}{|c|c|c|c|c|}
\hline Observed Value & Expected Value & $\mathrm{O}-\mathrm{E}$ & $(\mathrm{O}-\mathrm{E})^{2}$ & $(\mathrm{O}-\mathrm{E})^{2} / \mathrm{E}$ \\
\hline 3 & 5.07794 & -2.07794 & 4.317835 & 0.8503122 \\
20 & 17.62329 & 2.37671 & 5.648750 & 0.3205275 \\
0 & 0.29854 & -0.29854 & 0.089126 & 0.2985400 \\
4 & 5.07794 & -1.07794 & 1.161955 & 0.2288240 \\
19 & 17.62329 & 1.37671 & 1.895330 & 0.1075469 \\
0 & 0.29854 & -0.29854 & 0.089126 & 0.2985400 \\
7 & 5.96106 & 1.03894 & 1.079396 & 0.1810745 \\
20 & 20.68821 & -0.68821 & 0.473633 & 0.0228938 \\
0 & 0.35046 & -0.35046 & 0.122822 & 0.3504600 \\
11 & 5.96106 & 5.03984 & 25.39092 & 4.2594633 \\
16 & 20.68821 & -4.68821 & 21.97931 & 1.0624077 \\
0 & 0.35046 & -0.35046 & 0.122822 & 0.3504600 \\
4 & 5.96106 & -1.96106 & 3.845756 & 0.6451463 \\
21 & 20.68821 & 0.31179 & 0.097213 & 0.0046989 \\
2 & 0.35046 & 1.64954 & 2.720982 & 7.7640307 \\
5 & 5.96106 & -0.96106 & 0.923636 & 0.1549449 \\
22 & 20.68821 & 1.31179 & 1.720793 & 0.0831774 \\
0 & 0.35046 & -0.35046 & 0.122822 & 0.3504600 \\
\hline
\end{tabular}

$$
\text { Total }=\quad 17.3335
$$

"Proceedings of the 2002 American Society for Engineering Education Annual Conference \& Exposition Copyright @ 2002, American Society for Engineering Education" 
Now, the data from the section that used Taylor's Series is included on Table 3. It can be noticed that the same columns are employed. The change is in the number of rows. This change obviously affects the degrees of freedom. The freedom degrees for this new table are calculated as follows,

$$
\mathrm{g}_{\text {lib }}=(\text { columns }-1)(\text { rows }-1)=(2)(7)=14
$$

With these degrees of freedom and using a confidence level of 95\%, from a standard table for the Chi-square distribution the new statistic can be found:

$$
\mathrm{X}_{0.95}^{2}=23.68
$$

Table 4 shows the expected values as well as the computations made to obtain the new calculated statistic. Expected values were obtained in the same way as for Table 2. It can be seen that in this case, the calculated statistic is greater than the statistic obtained from standard tables for the Chisquare distribution $(68.6912<23.68)$. Therefore, it can be concluded that this set of data behaved in a distinct way. In other words, in this case there is a significant difference among the groups. It can be noticed that the bold numbers (which correspond to the group that used the Series) are large enough to surpass the statistic from the standard Chi-square table.

Table 3: Survey results for all the sections.

\begin{tabular}{|c|c|c|c|c|c|}
\cline { 2 - 5 } \multicolumn{1}{c|}{} & \multicolumn{3}{c|}{ Answers to Question 6 } & \multicolumn{1}{c|}{} \\
\hline Section & Yes & No & Don't Know & Totals & Situation \\
\hline 1 & 3 & 20 & 0 & 23 & Before \\
1 & 4 & 19 & 0 & 23 & After \\
2 & 7 & 20 & 0 & 27 & Before \\
2 & 11 & 16 & 0 & 27 & After \\
3 & 4 & 21 & 2 & 27 & Before \\
3 & 5 & 22 & 0 & 27 & After \\
4 & 2 & 22 & 0 & 24 & Before \\
4 & 21 & 3 & 0 & 24 & After \\
& 57 & 143 & -2 & 202 & \\
\hline & 0.28217 & 0.70792 & 0.0099 & & \\
\hline
\end{tabular}

The evidence seems to indicate that the use of Taylor's Series made a measurable difference with regard to the understanding of the condition $\mathrm{v}(0)=0$ and $\mathrm{a}(0) \neq 0$.

\section{Conclusions}

The study of motion is not a trivial problem. The road traveled by humanity in the construction of what is now known as "Classical Mechanics" proves this fact. Even Piaget, a scholar of the way in which humans build knowledge, mentions that there are obstacles in the formation of the notions of velocity, time, and space ${ }^{19}$. Therefore, it is understandable to find difficulties among students when they try to grasp the advanced concepts covered in a Dynamics course. Also, it is very interesting to find that many of their mental models, found in their survey answers, do not lack logic. Actually, rather than say that these mental models are wrong, it may be more appropriate to say that they are simply "incomplete".

"Proceedings of the 2002 American Society for Engineering Education Annual Conference \& Exposition Copyright (C) 2002, American Society for Engineering Education” 
Table 4: Expected value calculations for the all the sections.

\begin{tabular}{|c|c|c|c|c|}
\hline Observed Value & Expected Value & $\mathrm{O}-\mathrm{E}$ & $(\mathrm{O}-\mathrm{E})^{2}$ & $(\mathrm{O}-\mathrm{E})^{2} / \mathrm{E}$ \\
\hline 3 & 6.48991 & -3.48991 & 12.17947 & 1.8766781 \\
20 & 16.28216 & 3.71784 & 13.82233 & 0.8489251 \\
0 & 0.22770 & -0.22770 & 0.051847 & 0.2277000 \\
4 & 6.48991 & -2.48991 & 6.199652 & 0.9552754 \\
19 & 16.28216 & 2.71784 & 7.386654 & 0.4536655 \\
0 & 0.22770 & -0.22770 & 0.051847 & 0.2277000 \\
7 & 7.61859 & -0.61859 & 0.382653 & 0.0502263 \\
20 & 19.11384 & 0.88616 & 0.785279 & 0.0410843 \\
0 & 0.26730 & -0.26730 & 0.071449 & 0.2673000 \\
11 & 7.61859 & 3.38141 & 11.43393 & 1.5007939 \\
16 & 19.11384 & -3.11384 & 9.695999 & 0.5072763 \\
0 & 0.26730 & -0.26730 & 0.071449 & 0.2673000 \\
4 & 7.61859 & -3.61859 & 13.09419 & 1.7187161 \\
21 & 19.11384 & 1.88616 & 3.557599 & 0.1861268 \\
2 & 0.26730 & 1.73270 & 3.002249 & 11.2317590 \\
5 & 7.61859 & -2.61859 & 6.857014 & 0.9000370 \\
22 & 19.11384 & 2.88616 & 8.329919 & 0.4358056 \\
0 & 0.26730 & -0.26730 & 0.071449 & 0.2673000 \\
2 & 6.77208 & -4.77208 & 22.77274 & 3.3627405 \\
22 & 16.990080 & 5.00992 & 25.09929 & 1.4772914 \\
0 & 0.23760 & -0.23760 & 0.056454 & 0.2376000 \\
21 & 6.77208 & 14.22792 & 202.4337 & $\mathbf{2 9 . 8 9 2 3 9 8 0}$ \\
3 & 16.990080 & -13.9900 & 195.7223 & $\mathbf{1 1 . 5 1 9 8 5 5 0}$ \\
0 & 0.23760 & -0.23760 & 0.056454 & 0.2376000 \\
\hline & & & & Total \\
\hline
\end{tabular}

Now, from the statistical results it was found that Taylor's Series really was an aid to understanding the condition $\mathrm{v}(0)=0$ and $\mathrm{a}(0) \neq 0$. However, the Series' importance goes beyond the explanation of a single concept. Taylor's Series may be easily used to explain situations wherein acceleration is variable. Also, the "intuitive" notion of prediction was introduced by the Series.

In summary, among the properties of Taylor's Series that may be exploited in the classroom, it was found that:

1. It is a highly versatile tool.

2. It can be considered as a bridge between difficult to grasp concepts and intuition.

3. It allows one to go deeper into complex ideas.

It now remains to state that new approaches to applying Taylor's Series in the classroom need to be explored. And furthermore, it is possible to continue looking into the history of knowledge so that more "old" or "forgotten" techniques can be brought to life and given a new meaning by helping new generations understand timeless ideas and solve timeless problems.

"Proceedings of the 2002 American Society for Engineering Education Annual Conference \& Exposition Copyright $@$ 2002, American Society for Engineering Education” 
Bibliography

1. Bradley, C; Cross, T; and Philip, R. "Roger and me: a teacher's dilemma". Roeper Review 23 (4) (2001): 211 215.

2. Schwalbach, E. M. and Dosemagen, D. M. "Developing student understanding: contextualizing Calculus concepts". School Science and Mathematics 100 (2) (2000): 90-98.

3. Vonder Embse, C. B. "Dynamic visualizations of Calculus ideas". Mathematics Teacher 94 (7) (2001): $602-$ 607.

4. Anderson, M.; Bloom, L.; Mueller, U.; and Pedler, P. "The impact of the graphics calculator on the assessment of Calculus and modelling". International Journal of Mathematical Education in Science and Technology 30(4) (1999): 489-498.

5. Jones, T. and Jackson, S. "Rugby and Mathematics: a surprising link among Geometry, the conics, and Calculus". Mathematics Teacher 94 (8) (2001): 649-654.

6. Freudenthal, H. "Why to teach Mathematics so as to be useful". Educational Studies in Mathematics 1 (1/2) (1968): 3-8.

7. Cantoral, R.; Cordero, F.; Farfan, R. M.; and Imaz, C. "Cálculo-Análisis: Una revisión de la investigación educativa reciente en México". Cuadernos de Investigación CINVESTAV-IPN, Departamento de Matemática Educativa, México, D.F. 1991.

8. Koyré, A. Estudios de Historia del Pensamiento Científico. México, D. F.: Editorial Siglo XXI, Sixth Edition, 1984.

9. Koyré, A. Del Mundo Cerrado al Universo Infinito. México, D. F.: Editorial Siglo XXI, Fifth Edition, 1986.

10. Cantoral, R. "Acerca de las contribuciones actuales de una didáctica de antaño: El caso de la Serie de Taylor". Mathesis 11 (1) (1995): 55-101.

11. Cantoral, R. "Series de Taylor, un acercamiento constructivista". Cuadernos de Investigación CINVESTAVIPN, Departamento de Matemática Educativa, México, D.F. 1990.

12. Hibbeler, R. C. Engineering Mechanics: Dynamics. Upper Saddle River, NJ: Prentice Hall, Seventh Edition, 1995.

13. Higdon, A.; Stiles, W. B.; Davis, A. W.; Evces, C. R.; and Weese, J. A. Ingeniería Mecánica: Dinámica Vectorial. México, D. F.: Prentice Hall, Second Edition, 1984.

14. Beer, F. P. and Johnston, E. R. Vector Mechanics for Engineers: Dynamics. New York, NY: McGraw Hill, Fourth Edition, 1988.

15. Blackwood, O. H.; Kelly, W. C.; and Bell, R. M. Física General. México, D. F.: Compañía Editorial Continental, Fourth Edition, 1981.

16. Goncalves de Alvarenga, B. and Maximo Ribeiro Da Luz, A. Física General. México, D. F.: Editorial Harla, 1982.

17. Van Der Merwe, C. W. Física General. México, D. F.: McGraw Hill, 1985.

18. Tavernier, J. "The thinking of a physicist about Mathematics". Educational Studies in Mathematics 1 (1/2) (1968): 55-60.

19. Piaget, J. Psicología y Epistemología. Buenos Aires, Argentina: Editorial Emece, 1972.

Author Biography

MAXIMO J. ORTEGA is an assistant professor in the Department of Industrial Technology at Purdue University. He earned his Ph.D. from the State University of New York at Buffalo in 2001; a Master's degree from the Juarez Institute of Technology, Mexico; a Master's degree from the Research and Advances Studies Center, Mexico; and a Bachelor degree from the Chihuahua Institute of Technology, Mexico. He has 15 years of teaching experience.

"Proceedings of the 2002 American Society for Engineering Education Annual Conference \& Exposition Copyright (C) 2002, American Society for Engineering Education" 